\title{
CONTROLE INTEGRADO DE SPODOPTERA FRUGIPERDA (SMITH \& ABBOTT) UTILIZANDO-SE O PARASITÓIDE TELENOMUS REMUS NIXON ${ }^{1}$
}

\author{
MARIA DE LOURDES CORRÊA FIGUEIREDO ${ }^{2}$, IVAN CRUZ ${ }^{3}$ TEREZINHAMARIA CASTRO DELLA LUCIA ${ }^{4}$
}

\begin{abstract}
RESUMO - Este estudo foi conduzido em 1996 e 1997 para avaliar a eficiência da liberação de Telenomus remus Nixon (cerca de 200.000 adultos/ha), sozinho ou integrado ao vírus de poliedrose nuclear de Spodoptera frugiperda (VPNSf) ou a um inseticida químico seletivo, para o controle de Spodoptera frugiperda (Smith \& Abbott). Os experimentos foram conduzidos em delineamento experimental de blocos ao acaso, com seis tratamentos e quatro repetições. Foram avaliados os danos provocados pela praga às folhas (escala de $0 \mathrm{a} 5$ ) e o rendimento de espigas. De maneira geral, os danos provocados pela praga foram significativamente superiores nas parcelas testemunhas (nota média de 2,94 ). Não houve diferença significativa entre os demais tratamentos (média 1,04). De maneira semelhante, houve diferença significativa no rendimento de espiga entre testemunha $(7.165 \mathrm{~kg} / \mathrm{ha})$ e demais tratamentos (9.084 kg/ha). Não houve efeito dos tratamentos no comprimento da espiga e no dano às espigas.
\end{abstract}

Termos para indexação: Zea mays, controle biológico, manejo integrado de pragas, Baculovírus.

\section{INTEGRATED CONTROL OF SPODOPTERA FRUGIPERDA (SMITH \& ABBOTT) USING THE PARASITOID TELENOMUS REMUS NIXON}

\begin{abstract}
This study was conducted in 1996 and 1997 to evaluate the efficiency of releasing Telenomus remus Nixon (around 200,000 adults/ha) alone or integrated toSpodoptera frugiperda (Smith \& Abbott) Spodoptera frugiperda nuclear polyhedrosis virus (SFNPV) or to a selective insecticide to control the insect. The experimental design was a randomized complete block with six treatments and four replications. Leaf damage caused by the pest (visual scale from 0 to 5 ) and the grain yield were evaluated. In general, the damage was significantly higher in the check plots (average of 2.94) than in the other treatments (average of 1.04). Similarly, there was significant difference in yield between check plots $(7,165 \mathrm{~kg} / \mathrm{ha})$ and the other treatments $(9,084 \mathrm{~kg} / \mathrm{ha})$. There was no difference in ear length and damage caused to the ear among treatments.
\end{abstract}

Index terms: Zea mays, biological control, integrated pest management, Baculovirus.

\section{INTRODUÇÃO}

Spodoptera frugiperda (Smith \& Abbott) (Lepidoptera: Noctuidae), conhecida como lagartado-cartucho, é uma praga que ataca diversas culturas, especialmente a do milho (Carvalho, 1970; Cruz, 1980), ocasionando perdas na produção que variam

\footnotetext{
${ }^{1}$ Aceito para publicação em 18 de janeiro de 1999.

${ }^{2}$ Eng. Agr., M.Sc., Embrapa-Centro Nacional de Pesquisa de Milho e Sorgo (CNPMS), Caixa Postal 151, CEP 35701-970 Sete Lagoas, MG. E-mail: lude@enpms.embrapa.br

${ }^{3}$ Eng. Agr., Ph.D., Embrapa-CNPMS.

${ }^{4}$ Bióloga, Ph.D., Universidade Federal de Viçosa (UFV), CEP 35570-000 Viçosa, MG
}

de 15\% a 34\% (Carvalho, 1970; Cruz \& Turpin, 1982; Cruz et al., 1996) e culminando em grandes prejuízos aos agricultores. O seu controle em milho tem sido realizado exclusivamente com produtos químicos, que são aplicados logo que detectada sua ocorrência na cultura. No entanto, a má regulagem dos equipamentos, a escolha incorreta de produtos químicos e a condução nem sempre adequada da cultura têm aumentado o número médio de aplicações de inseticidas, sem um adequado controle da praga (Cruz, 1995a, 1997b).

Na concepção de manejo integrado, a meta não é simplesmente aniquilar a praga; o mais importante é a redução da população a um limite compatível com a produção econômica da cultura e a conse- 
qüente manutenção da qualidade ambiental (Cruz, 1995a, 1995b). Entre os agentes de controle biológico, pesquisas têm sido conduzidas com o vírus de poliedrose nuclear de $S$. frugiperda (VPNSf), o qual tem apresentado grande potencial de controle dessa praga (Gardner et al., 1984; Moscardi \& Kastelic, 1985; Cruz et al., 1997), e com vários outros inimigos naturais da classe Insecta (Cruz, 1995a). Entre esses, são considerados agentes reguladores da população de S. frugiperda os parasitóides de ovos, e, mais especificamente, Telenomus remus Nixon (Hymenoptera: Scelionidae), que atuam efetivamente sobre os ovos, parasitando inclusive aqueles das camadas internas, além de apresentar alta capacidade de dispersão e de busca pelo hospedeiro (Cruz \& Figueiredo, 1994; Cruz, 1995a).

Diversos estudos têm examinado as possibilidades de integração entre diferentes táticas de controle de pragas, como, por exemplo, as interações tróficas entre plantas, pragas e seus inimigos naturais, sejam parasitóides (Karowe \& Schoonhoven, 1992) ou predadores (Isenhour et al., 1989). Segundo Murray et al. (1995), devido à segurança, especificidade e o impacto mínimo sobre os agentes de controle biológico, o uso de vírus de poliedrose nuclear tem sido encorajado para o controle de pragas. No entanto, para os autores, a sua aplicação de maneira incorreta pode afetar adversamente o parasitismo, especialmente quando se trata de um parasitóide de lagartas, uma vez que o vírus pode matar as larvas em desenvolvimento dentro do corpo do hospedeiro. Por outro lado, um parasitismo prévio pode diminuir a ação da doença virótica, pela eliminação do hospedeiro (Teakle et al., 1985b). Murray et al. (1995), estudando as interações entre o vírus de poliedrose nuclear e três parasitóides de H. armigera (Hubner), relataram que o uso do vírus poderia pôr em risco a sobrevivência dos parasitóides, se a aplicação ocorresse três dias após o parasitismo. Um atraso em três dias na aplicação ajudaria a conservar os parasitóides, embora tal demora pudesse resultar na necessidade de maior quantidade do produto, pelo tamanho mais desenvolvido das lagartas (Teakle et al., 1985a).

De maneira geral, a integração de controle químico e biológico é limitada pelo uso de inseticidas de amplo espectro de ação (Brunner, 1994). No entanto, progressos significativos têm sido feitos nos últimos anos com o desenvolvimento de produtos seletivos, aumentando significativamente as possibilidades da integração de controle biológico e inseticidas químicos (Croft, 1990; Dutcher, 1993).

O objetivo deste trabalho foi avaliar, em condições de campo, a eficiência do parasitóide de ovos T. remus, sozinho ou integrado a outros métodos, no controle de $S$. frugiperda.

\section{MATERIAL E MÉTODOS}

A pesquisa foi desenvolvida na Embrapa-Centro Nacional de Pesquisa de Milho e Sorgo, Sete Lagoas, MG, durante os anos de 1996 e 1997. Os espécimes do parasitóide T. remus e do hospedeiro $S$. frugiperda utilizados foram provenientes da criação de laboratório, onde foram mantidos sob temperatura de $25 \pm 2^{\circ} \mathrm{C}$, umidade relativa de $70 \pm 10 \%$ e fotofase de 12 horas. Na criação massal do parasitóide utilizaram-se posturas de $S$. frugiperda como fonte de parasitismo. As lagartas de $S$. frugiperda foram alimentadas com dieta artificial.

O experimento foi conduzido em plantios de milho, híbrido BR 205, utilizando-se uma adubação de base com $300 \mathrm{~kg} /$ ha da fórmula 8-28-16 + Zn, de acordo com análise do solo. Aos 40 dias após o plantio, foi realizada uma cobertura com $200 \mathrm{~kg} / \mathrm{ha}$ de sulfato de amônia. Quando necessário, efetuou-se irrigação por aspersão convencional. Utilizou-se delineamento em blocos casualizados, com seis tratamentos e quatro repetições, e cada parcela experimental consistiu de quatro fileiras de milho de cinco metros de comprimento, com espaçamento de um metro, numa densidade de 25 plantas por fileira, deixando-se uma distância de $10 \mathrm{~m}$ entre parcelas. Os tratamentos foram: testemunha (nenhum tratamento); T. remus (200.000 adultos/ha); T. remus $(200.000$ adultos/ha $)+$ VPNSf $\left(2,5 \times 10^{11}\right.$ poliedros/ha); VPNSf $\left(2,5 \times 10^{11}\right.$ poliedros/ha); T. remus (200.000 adultos/ha) + lambdacialotrina $(3,75 \mathrm{~g} / \mathrm{ha})$ e lambdacialotrina (7,5 g/ha).

Em todas as parcelas, incluindo a testemunha, efetuouse uma infestação artificial com 20 posturas de S. frugiperda (média de 100 ovos/postura), distribuídas aleatoriamente entre as plantas (uma postura por planta); esse valor correspondeu a $20 \%$ de plantas infestadas, nível em que se recomenda o início do controle da praga em milho (Cruz, 1995a). A infestação foi realizada em plantas com 30 dias após a emergência (média de 52,2 cm de altura ou no estágio de 5-6 folhas), por serem mais susce- 
tíveis ao ataque de $S$. frugiperda (Cruz \& Turpin, 1982) Cada postura foi fixada no lado externo da folha, com um grampeador. Nos tratamentos envolvendo o parasitóide, foi realizada uma única liberação, com 400 adultos (razão sexual 0,52 ), no ponto central de cada parcela, logo após a infestação. O VPNSf e o inseticida químico foram aplicados sete dias após a infestação, utilizando-se um pulverizador costal, pressurizado com $\mathrm{CO}_{2}$, mantendo-se a pressão a 40 psi. O volume de calda foi de $320 \mathrm{~L} / \mathrm{ha}$.

Durante toda a fase experimental, as parcelas foram monitoradas com a finalidade de diminuir a interferência de infestações naturais, eliminando-se da área as posturas da praga (três coletas semanais). Aos 15 e 22 dias após a infestação, procedeu-se as avaliações do dano provocado por $S$. frugiperda em todas as plantas de cada parcela, considerando os danos nas seis folhas centrais, de acordo com a seguinte escala de notas (Carvalho, 1970): 0 - plantas sem folhas danificadas; 1 - plantas com raspadura nas folhas; 2 - plantas apresentando furo nas folhas; 3 - plantas apresentando dano nas folhas e alguma lesão no cartucho; 4 - plantas apresentando cartucho destruído; 5 - plantas mortas. Na colheita, foram retiradas de cada parcela 40 espigas em estado leitoso ( $70 \%$ a $80 \%$ de umidade) para avaliar o dano, o comprimento e o peso da espiga sem palha. O dano nas espigas foi determinado com base em escala de notas modificada daquela proposta por Widstron (1967), considerando a penetração do inseto na espiga, sendo a nota 1 , com penetração até $1 \mathrm{~cm}$ além da ponta da espiga; nota 2 , até $2 \mathrm{~cm}$, até a nota $\mathrm{n}$. A avaliação foi feita com o auxílio de uma régua milimetrada. Todas as variáveis foram submetidas à análise de variância, e as médias separadas pelo teste de Duncan, a 5\% de probabilidade.

\section{RESULTADOS E DISCUSSÃo}

Aos 15 dias após a infestação, o dano causado pelas lagartas nas plantas não foi expressivo (Tabela 1); portanto, a avaliação nesse período foi inadequada para discutir os resultados. Recomenda-se a avaliação a partir dos 20 dias, período em que as lagartas mais desenvolvidas ocasionam maior dano às plantas. Apesar disso, a avaliação aos 15 dias foi suficiente para mostrar diferenças entre os tratamentos. No ano de 1996, o dano médio geral variou de 1,04 a 1,62; esses valores corresponderam ao nível de dano em que as plantas estavam com raspaduras e com furos nas folhas, respectivamente. A média geral de dano foi de 1,34. Os menores valores de dano foram obtidos no tratamento onde foi aplicado
T. remus com o lambdacialotrina, de 1,04, seguido do tratamento com lambdacialotrina (7,5 g i.a./ha) e dos tratamentos onde houve liberação de T. remus. Nas parcelas testemunhas, a nota média de danos foi de 1,5, e nas parcelas com VPNSf, de 1,62. A ocorrência do predador Doru luteipes (Scudder) (Dermaptera: Forficulidae) na cultura do milho, o que é comum na região, provavelmente foi um dos motivos pelo qual as parcelas da testemunha não apresentaram dano considerável, quando comparado aos demais tratamentos. Em função das notas de danos relativamente baixas dentro da escala, e considerando que as lagartas ainda estavam pequenas na data da avaliação, foi feita nova avaliação aos 22 dias, atribuindose notas às parcelas como um todo. A nota média de danos das parcelas testemunhas $(3,12)$ diferiu significativamente das demais que, por sua vez, não diferiram entre si (Tabela 1), cujo dano médio foi 1,47.

No ano de 1997, o dano médio na primeira avaliação ficou abaixo de 1,0, e somente a testemunha diferiu dos demais tratamentos (Tabela 1). Mesmo na segunda avaliação, apesar de haver nítida diferença entre o dano provocado às plantas nas parcelas testemunhas e demais parcelas, ainda assim foram inferiores aos do ano anterior. A época em que o experimento foi infestado com as posturas de S. frugiperda coincide com um dos períodos (marçoabril) em que a população do predador D. luteipes é alta (Cruz \& Oliveira, 1997), o que pode ter agido de modo a diminuir a população da praga. Essa diferença pode ser visualizada pela análise combinada, considerando-se os anos como tratamentos. Na primeira avaliação, a nota média de dano da lagarta-do-cartucho em 1996 foi de 1,34, e em 1997 foi de 0,41 , diferindo significativamente uma da outra. $\mathrm{Na}$ segunda avaliação, também houve diferença significativa, com a média de dano de 1,75 e 0,96 em 1996 e 1997, respectivamente.

Considerando a média dos dois anos, verificase na primeira avaliação que quando foi utilizado somente o inseticida químico, em dose normal, ou quando o produto foi utilizado na metade da dose, aplicado após a liberação do parasitóide, foram obtidas as menores notas de dano da praga: 0,70 e 0,69, respectivamente. Entretanto, isso não ocorreu na segunda avaliação, cujas médias diferiram somente da testemunha. 
Considerando o valor médio dos dois anos, na avaliação realizada aos 22 dias após a infestação, de acordo com a escala de notas, os danos corresponderam às folhas raspadas $\mathrm{e}$ a alguns furos na folha, mostra que todos os tratamentos foram eficientes no controle da praga. Quando aplicado na mesma dose e com equipamentos adotados neste trabalho, o VPNSf proporcionou $71 \%$ de mortalidade de lagartas de S. frugiperda (Cruz et al., 1997), o que indica a eficiência do produto no controle dessa praga.

A eficiência do T. remus em liberações na cultura do milho e em outras culturas no controle de S. frugiperda já foi observada por Alam (1978), Yaseen (1978), Dass \& Parshad (1984) e Kumar et al. (1984), e no controle de $S$. litura (Fabricius), por Patel et al. (1979) e Krishnamoorthy \& Mani (1985).

Ao se integrar o parasitóide de ovos T. remus ao inseticida químico lambdacialotrina ou ao VPNSf, verificou-se que não houve ganhos no controle da praga, em virtude da eficiência de cada tratamento quando aplicados sozinhos. Talvez a utilização da dose reduzida ( $3,75 \mathrm{~g}$ i.a./ha) do inseticida químico ou do vírus, ou mesmo uma menor quantidade de parasitóides liberados como tratamento único pudesse mostrar o efeito benéfico da integração. No entanto, Cruz et al. (1997) observaram aumento médio na taxa de mortalidade larval de $16,4 \%$ por causa da ocorrência de parasitóides em áreas pulverizadas com o VPNSf, demonstrando a compatibilida- de dos dois métodos integrados no controle da lagarta-do-cartucho. Entretanto, Mertz et al. (1995) não observaram resultado adicional no controle de Ostrinia nubilalis ( $\mathrm{Hbn}$.), quando integraram o parasitóide de ovos Trichogramma brassicae Bezdenko com Bacillus thuringiensis Berliner.

Os resultados obtidos neste experimento indicam a possibilidade de se utilizar o parasitóide T. remus como uma alternativa adicional para controlar S. frugiperda. Uma das limitações dos demais tratamentos diz respeito ao equipamento de aplicação, especialmente quando as infestações ocorrem em estágios de desenvolvimento mais avançados da cultura do milho, o que impossibilita a pulverização com os equipamentos convencionais (Cruz, 1997b). Especificamente em relação ao vírus, cujo modo de ação é por ingestão, a aplicação incorreta, ou seja, fora do local onde se encontra a praga, pode não surtir o efeito esperado pela nãoingestão do bioinseticida. Com os inseticidas químicos deve-se ainda considerar seus efeitos adversos ao meio ambiente e ao ser humano, apesar de lambdacialotrina ser seletivo a alguns dos principais inimigos naturais de $S$. frugiperda (Cruz, 1997a).

A utilização de $T$. remus demanda um manejo adequado na cultura, com monitoramento constante para determinar a época mais adequada para sua liberação. No entanto, a atuação do inseto sobre ovos, eliminando a praga antes que ela cause dano à plan-

TABELA 1. Notas médias de danos provocados por Spodoptera frugiperda em plantas de milho, aos 15 e 22 dias após a infestação (DAI) com ovos em parcelas sujeitas a diferentes tratamentos. Sete Lagoas, MG ${ }^{\mathbf{1}}$.

\begin{tabular}{|c|c|c|c|c|c|c|c|}
\hline \multirow[t]{2}{*}{ Tratamento } & \multirow[t]{2}{*}{ Dose/ha } & \multicolumn{3}{|c|}{ Nota de dano foliar 15 DAI } & \multicolumn{3}{|c|}{ Nota de dano foliar 22 DAI } \\
\hline & & 1996 & 1997 & Média & 1996 & 1997 & Média \\
\hline Testemunha & & $1,50 \mathrm{AB}$ & $0,72 \mathrm{~A}$ & $1,11 \mathrm{~A}$ & $3,12 \mathrm{~A}$ & $2,75 \mathrm{~A}$ & $2,94 \mathrm{~A}$ \\
\hline T. remus & 200.000 adultos & $1,43 \mathrm{ABC}$ & $0,44 \mathrm{~B}$ & $0,94 \mathrm{AB}$ & $1,50 \mathrm{~B}$ & $0,50 \mathrm{~B}$ & $1,00 \mathrm{~B}$ \\
\hline T. remus + VPNSf & $200.000+2,5 \times 10^{11}$ pol. & $1,32 \mathrm{ABC}$ & $0,39 \mathrm{~B}$ & $0,86 \mathrm{BC}$ & $1,62 \mathrm{~B}$ & $0,50 \mathrm{~B}$ & $1,06 \mathrm{~B}$ \\
\hline VPNSf & $2,5 \times 10^{11}$ pol. & $1,62 \mathrm{~A}$ & $0,31 \mathrm{~B}$ & $0,97 \mathrm{AB}$ & $1,75 \mathrm{~B}$ & $0,50 \mathrm{~B}$ & $1,12 \mathrm{~B}$ \\
\hline T. remus + lambdacialotrina & $200.000+3,75 \mathrm{~g}$ & $1,04 \mathrm{C}$ & $0,34 \mathrm{~B}$ & $0,69 \mathrm{C}$ & $1,25 \mathrm{~B}$ & $0,75 \mathrm{~B}$ & $1,00 \mathrm{~B}$ \\
\hline Lambdacialotrina & $7,5 \mathrm{~g}$ & $1,13 \mathrm{BC}$ & $0,27 \mathrm{~B}$ & $0,70 \mathrm{C}$ & $1,25 \mathrm{~B}$ & $0,75 \mathrm{~B}$ & $1,00 \mathrm{~B}$ \\
\hline Média & & $1,34 \mathrm{a}$ & $0,41 \mathrm{~b}$ & & $1,75 \mathrm{a}$ & $0,96 \mathrm{~b}$ & \\
\hline $\mathrm{CV}(\%)$ & & 10,1 & 11,0 & 10,5 & 8,4 & 14,27 & 11,12 \\
\hline
\end{tabular}

${ }^{1}$ Médias seguidas pela mesma letra, maiúscula na coluna e minúscula na linha, não diferem significativamente entre si a $5 \%$, segundo o teste de Duncan. 
ta, torna esse inimigo natural promissor, abrindo novas perspectivas de controle de $S$. frugiperda, em substituição aos inseticidas ou a redução do seu uso.

Nos dois anos, não houve diferença significativa no comprimento das espigas entre os tratamentos (Tabela 2), que apresentaram uma média de $18,5 \mathrm{~cm}$, em 1996, e de 18,0 cm, em 1997. Esses resultados assemelham-se aos obtidos por Cruz (1980), em que o comprimento da espiga não foi afetado pela infestação da praga. O dano ocasionado às espigas de milho pelo complexo de pragas, representado principalmente por $S$. frugiperda e Helicoverpa zea Boddie (Lepidoptera: Noctuidae), foi maior em 1996, mas não o suficiente para mostrar diferenças entre os tratamentos, nos dois anos (Tabela 2).

Os rendimentos relacionados aos respectivos tratamentos foram diferentes em ambos os anos, sendo maior em 1996, com $9.299 \mathrm{~kg} / \mathrm{ha}$, ao passo que em 1997 foi de $8.229 \mathrm{~kg} / \mathrm{ha}$; o rendimento da testemunha foi inferior ao dos demais tratamentos, os quais não diferiram significativamente entre si (Tabela 2). A média dos tratamentos sem a testemunha, ou seja, somente onde houve controle da praga, foi de $9.633 \mathrm{~kg} / \mathrm{ha}$, enquanto a média da testemunha foi de $7.630 \mathrm{~kg} / \mathrm{ha}$, no ano de 1996 . Esse ganho de rendimento foi de $21 \%$ a mais do que sem o controle da praga. O mesmo valor foi encontrado em 1997, cuja média dos rendimentos dos tratamentos sem a testemunha foi de $8.534 \mathrm{~kg} / \mathrm{ha}$ e o rendimento médio da testemunha foi de $6.700 \mathrm{~kg} / \mathrm{ha}$. Ou seja, não houve diferença significativa entre os rendimentos dos tratamentos em que houve controle da praga, nos dois anos, os quais foram significativamente superiores aos da testemunha (Tabela 2).

Resultados semelhantes foram obtidos por Carvalho (1970), que constatou percentual de perda de grãos, causado pela praga, de $29,7 \%$, quando o ataque ocorreu 49 dias após o plantio. Cruz $\&$ Turpin (1982), trabalhando com infestações por dois anos consecutivos, obtiveram valor médio de $18,7 \%$. Cruz et al. (1996), estudando o efeito do nível de saturação de alumínio sobre os danos de $S$. frugiperda em milho, verificaram que as perdas na produção de grãos causadas por essa praga foram em torno de $18 \%$. Segundo Cruz (1980), a redução nos rendimentos de grãos em parcelas infestadas com ovos de $S$. frugiperda foi relacionada com a diminuição do número de grãos por espiga. Como as demais variáveis estudadas não foram influenciadas pelos diferentes tratamentos, é provável que o número de grãos na espiga, também nesse experimento, possa ter sido o fator principal a explicar as diferenças ocorridas nos rendimentos.

TABELA 2. Comprimento, profundidade de dano por inseto e rendimento de espigas de milho em diferentes parcelas sujeitas a diferentes tratamentos para o controle de Spodoptera frugiperda. Sete Lagoas, MG'.

\begin{tabular}{|c|c|c|c|c|c|c|c|c|c|}
\hline \multirow[t]{2}{*}{ Tratamento } & \multicolumn{3}{|c|}{$\begin{array}{l}\text { Comprimento de espiga } \\
(\mathrm{cm})\end{array}$} & \multicolumn{3}{|c|}{$\begin{array}{l}\text { Profundidade de danos } \\
\text { na espiga }(\mathrm{cm})\end{array}$} & \multicolumn{3}{|c|}{ Peso de espigas (kg/ha) } \\
\hline & 1996 & 1997 & Média & 1996 & 1997 & Média & 1996 & 1997 & Média \\
\hline Testemunha & $18,7 \mathrm{~A}$ & $18,0 \mathrm{~A}$ & $18,3 \mathrm{~A}$ & $1,41 \mathrm{~A}$ & $0,48 \mathrm{~A}$ & $0,95 \mathrm{~A}$ & 7.630B & $6.700 \mathrm{~B}$ & $7.165 \mathrm{~B}$ \\
\hline T. remus & $18,3 \mathrm{~A}$ & $17,5 \mathrm{~A}$ & $17,9 \mathrm{~A}$ & $1,33 \mathrm{~A}$ & $0,62 \mathrm{~A}$ & $0,97 \mathrm{~A}$ & $9.467 \mathrm{~A}$ & $8.757 \mathrm{~A}$ & $9.112 \mathrm{~A}$ \\
\hline T. remus + VPNSf & $18,5 \mathrm{~A}$ & $18,0 \mathrm{~A}$ & $18,2 \mathrm{~A}$ & $1,33 \mathrm{~A}$ & $0,92 \mathrm{~A}$ & $1,13 \mathrm{~A}$ & $9.553 \mathrm{~A}$ & $8.303 \mathrm{~A}$ & $8.928 \mathrm{~A}$ \\
\hline VPNSf & $18,2 \mathrm{~A}$ & $18,3 \mathrm{~A}$ & $18,2 \mathrm{~A}$ & $1,54 \mathrm{~A}$ & $0,70 \mathrm{~A}$ & $1,12 \mathrm{~A}$ & $9.242 \mathrm{~A}$ & $8.381 \mathrm{~A}$ & $8.812 \mathrm{~A}$ \\
\hline T. remus + lambdacialotrina & $18,9 \mathrm{~A}$ & $18,3 \mathrm{~A}$ & $18,6 \mathrm{~A}$ & $1,55 \mathrm{~A}$ & $0,88 \mathrm{~A}$ & $1,22 \mathrm{~A}$ & $9.838 \mathrm{~A}$ & $8.615 \mathrm{~A}$ & $9.226 \mathrm{~A}$ \\
\hline Lambdacialotrina & $18,2 \mathrm{~A}$ & $18,0 \mathrm{~A}$ & $18,1 \mathrm{~A}$ & $1,29 \mathrm{~A}$ & $0,46 \mathrm{~A}$ & $0,88 \mathrm{~A}$ & $10.064 \mathrm{~A}$ & $8.616 \mathrm{~A}$ & $9.340 \mathrm{~A}$ \\
\hline Média & $18,5 \mathrm{a}$ & $18,0 \mathrm{a}$ & & $1,41 \mathrm{a}$ & $0,68 \mathrm{~b}$ & & $9.299 \mathrm{a}$ & $8.229 \mathrm{~b}$ & \\
\hline CV (\%) & 2,5 & 4,4 & 3,5 & 30,7 & 31,9 & 32,8 & 10,7 & 11,7 & 11,2 \\
\hline
\end{tabular}

${ }^{1}$ Médias seguidas pela mesma letra, maiúscula na coluna e minúscula na linha, não diferem significativamente entre si a $5 \%$, segundo o teste de Duncan. 
Os resultados obtidos em termos de rendimento de espigas como conseqüência do pouco dano ocasionado à planta de milho em parcelas onde foram liberados os parasitóides confirmam a viabilidade de uso de $T$. remus no controle biológico de S. frugiperda em milho, pois, sozinho, proporcionou rendimento igual aos outros métodos utilizados atualmente no controle dessa praga. A eficiência do controle biológico com parasitóides tem sido observada em relação a diversas pragas, principalmente O. nubilalis, na cultura do milho. Bigler (1986) observou redução no dano às plantas de $60 \%$ a $90 \%$, após liberações de Trichogramma maidis Pintureau e Voegele, enquanto Ravensberg \& Berger (1988) observaram uma redução de plantas infestadas de até $60 \%$. Hawlitzky et al. (1994), utilizando T. brassicae, em três liberações de $100.000 /$ ha, obtiveram até $80 \%$ de eficiência no controle dessa mesma praga.

Quando o parasitóide foi integrado ao inseticida químico ou ao VPNSf, não houve acréscimo no controle, em função da eficiência de cada método utilizado isoladamente. É possível que combinações desse parasitóide, em populações inferiores à utilizada neste trabalho, com o VPNSf ou inseticida seletivo em dose reduzida, também sejam estratégias adequadas ao controle efetivo de $S$. frugiperda na cultura do milho.

Considerando o aparecimento recente de $T$. remus parasitando ovos de $S$. frugiperda no Brasil, diferentes estratégias de liberação com $T$. remus devem ser ainda estudadas, para que novas medidas de controle sejam adotadas, incluindo o controle biológico com esse inimigo natural como medida eficiente, de fácil utilização, isenta de efeitos negativos ao meio ambiente e de baixo custo.

\section{CONCLUSÕES}

1. O parasitóide de ovos T. remus é viável para uso em programas de manejo integrado de $S$. frugiperda na cultura de milho no Brasil.

2. Numa densidade de infestação de uma postura de $S$. frugiperda por metro quadrado, a utilização de T. remus, VPNSf ou do inseticida lambda- cialotrina, propiciam igualmente um controle eficiente da praga na cultura de milho.

\section{REFERÊNCIAS}

ALAM, M.M. Attempts at the biological control of major insect pests of maize in Barbados. Proceedings of the Caribbean Food Crop Society, v.15, p.127-135, 1978

BIGLER, F. Mass production of Trichogramma maidis Pint. et Voeg. and its field application against Ostrinia nubilalis Hbn. in Switzerland. Journal of Applied Entomology, Hamburg, v.101, n.1, p.23-29, 1986.

BRUNNER, J.F. Integrated pest management in tree fruit crops. Food Reviews International, v.10, n.2, p.135157, 1994.

CARVALHO, R.P.L. Danos, flutuação da população, controle e comportamento de Spodoptera frugiperda (J.E. Smith, 1797) e susceptibilidade de diferentes genótipos de milho, em condições de campo. Piracicaba: ESALQ-USP, 1970. 170p. Tese de Doutorado.

CROFT, B.A. Arthropod biological control agents and pesticides. New York: Wiley \& Sons, 1990. 732p

CRUZ, I. A lagarta-do-cartucho na cultura do milho. Sete Lagoas: Embrapa-CNPMS, 1995a. 45p (Embrapa-CNPMS. Circular técnica, 21)

CRUZ, I. Impact of fall armyworm, Spodoptera frugiperda (Smith \& Abbot 1797), on grain yield in field corn. West Lafaytte, IN: Purdue University, 1980. 162p. M.Sc. Thesis

CRUZ, I. Manejo de pragas na cultura de milho. In FANCELLI, A.L.; DOURADO NETO, D. (Coords.). Tecnologia da produção de milho. Piracicaba: USP-ESALQ, 1997a. p.18-39.

CRUZ, I. Manejo integrado da lagarta-do-cartucho do milho. In: SEMINÁRIO SOBRE A CULTURA DO MILHO "SAFRINHA", 4., 1997, Campinas. Anais. Campinas: IAC/CDV, 1997b. p.189-195.

CRUZ, I. Manejo integrado de Pragas de milho com ênfase para o controle biológico. In: CICLO DE PALESTRAS SOBRE O CONTROLE BIOLÓGICO DE PRAGAS, 4., 1995, Campinas, SP. Anais. Campinas: SEB/Instituto Biológico, 1995b. p.48-92.

CRUZ, I.; FIGUEIREDO, M.L.C. Centro Nacional de Pesquisa de Milho e Sorgo (Sete Lagoas, MG). Estu- 
dos preliminares do parasitóide Telenomus $\mathrm{sp}$. Nixon sobre ovos de Spodoptera frugiperda. Relatório Técnico Anual do CNPMS, 1992/1993, Sete Lagoas, v.6, p.104-105, 1994.

CRUZ, I., FIGUEIREDO, M.L.C.; VALICENTE, F.H.; OLIVEIRA, A.C. Application rate trials with a nuclear polyhedrosis virus to control Spodoptera frugiperda (Smith) on maize. Anais da Sociedade Entomológica do Brasil, Jaboticabal, v.26, n.1, p.145-152, 1997.

CRUZ, I.; OLIVEIRA, A.C. Flutuação populacional do predador Doru luteipes (Scudder) em plantas de mi1ho. Pesquisa Agropecuária Brasileira, Brasília, v.32, n.4, p.363-368, 1997

CRUZ, I.; OLIVEIRA, L.J.; OLIVEIRA, A.C.; VASCONCELOS, C.A. Efeito do nível de saturação de alumínio em solo ácido sobre os danos de Spodoptera frugiperda (J.E. Smith) em milho. Anais da Sociedade Entomológica do Brasil, Jaboticabal, v.25, n.2, p.293-297, 1996

CRUZ, I.; TURPIN, F.T. Efeito da Spodoptera frugiperda em diferentes estágios de crescimento da cultura de milho. Pesquisa Agropecuária Brasileira, Brasília, v.17, n.3, p.355-359, 1982.

DASS, R.; PARSHAD, B. Rearing of important lepidopterous pests on known artificial diet and screening for preferred hosts of the parasite, Telenomus remus Nixon (Hymenoptera: Scelionidae). Journal of Entomological Research, New Delhi, v.8, n.1, p.89-92, 1984.

DUTCHER, J.D. Recent examples of conservation of Arthropod natural enemies in agriculture. In: LUMSDEN, R.D.; VAUGHN, J.L. (Eds.). Pest management: biologically based tecnologies Washington: American Chemical Society, 1993 p.101-108

GARDNER, W.A.; NOBLET, R.; SCHWEHR, R.D. The potential of microbial agents in managing populations of the fall armyworm. Florida Entomologist, Gainesville. v.67, n.3, p.325-332, 1984.

HAWLITZKY, N.; DORVILLE F.M.; VAILLANT, J Statistical study of Trichogramma brassicae efficiency in relation with characteristics of the European Corn Borer Egg Masses. Researches on Population Ecology, Tokyo, v.36, n.1, p.79-85, 1994.
ISENHOUR, D.J.; WISEMAN, B.R.; LAYTON, R.C. Enhanced predation by Orius insiosus (Hymenoptera: Anthocoridae) on larvae of Heliothis zea and Spodoptera frugiperda (Lepidoptera: Noctuidae) caused by prey feeding on resistant corn genotypes. Environmental Entomology, College Park, v.18, n.3, p.418-422, 1989

KAROWE, D.N.; SCHOONHOVEN, L.M. Interaction among three trophic levels: the influence of host plant on performance of Pieris brassicae and its parasitoid, Cotesia glomerata. Entomologia Experimentalis Applicata, Dordrecht, v.62, n.3, p.241-251, 1992.

KRISHNAMOORTHY, A.; MANI, M. Feeding behaviour of Chrysopa scelestes Banks on the parasitized eggs of some lepidopterous pests. Entomon, Trivandrum, v.10,n.1,p.17-19, 1985.

KUMAR, D.A.; DIVAKAR, B.J.; PAWAR, A.D. Observation on the storage of life stages of Telenomus remus Nixon (Hymenoptera: Scelionidae) under low temperature. Plant Protection Bulletin, India, v.36, n.4, p.13-14,1984

MERTZ, B.P.; FLEISCHHER, S.J.; CALVIN, D.D.; RIDGWAY, R.L. Field assessment of Trichogramma brassicae (Hymenoptera: Trichogrammatidae) and Bacillus thuringiensis for control of Ostrinia nubilalis (Lepidoptera: Pyralidae) in sweet corn. Journal of Economic Entomology, College Park, v.88, n.6, p.1616-1625, 1995.

MOSCARDI, F.; KASTELIC, J.G. Ocorrência de vírus de poliedrose nuclear e vírus de granulose em populações de Spodoptera frugiperda atacando soja na região de Sertaneja, PR. In: EMBRAPA. Centro Nacional de Pesquisa de Soja (Londrina, PR). Resultados de pesquisa de soja 1984/1985. Londrina, 1985. p.128. (Embrapa-CNPSo. Documentos, 15).

MURRAY, D.A.H.; MONSOUR, C.J.; TEAKLE, R.E.; RYNNE, K.P.; BEAN, J.A. Interactions between nuclear polyhedrosis virus and three larval parasitoids of Helicoverpa armigera (Hubner) (Lepidoptera: Noctuidae). Journal of the Australian Entomological Society, Brisbane, v.34, n.4,p.319-322, 1995

PATEL, R.C.; YADAV, D. N.; SARAMMA, P.U. Impact of mass releases of Chelonus heliopae Gupta and Telenomus remus Nixon against Spodoptera litura 
(Fabricius). Journal of Entomological Research, New Delhi, v.3, n.1, p.53-56, 1979.

RAVENSBERG, W.J.; BERGER, H.K. Biological control of the european corn borer (Ostrinia nubilalis Hbn, Pyralidae) with Trichogramma maidis Pintureau and Voegele in Austria in 1980-1985. In: INTERNATIONAL SYMPOSIUM ON TRICHOGRAMMA AND OTHER EGG PARASITES, 2., 1986, Guangzhou, China. Les Colloques. Paris: institut National de la Recherche Agronomique, 1988. p.557-564. (Les Colloques de l'INRA, 43)

TEAKLE, R.E.; JENSEN, J.M.; GLES, J.E. Susceptibility of Heliothis armiger to a commercial nuclear polyhedrosis virus. Journal of Invertebrate Pathology, Nova York, v.46, p.166-173, 1985a

TEAKLE, R.E.; JENSEN, J.M.; MULDER, J.C Susceptibility of Heliothis armiger (Lepidoptera: Noctuidae) on sorghum to nuclear polyhedrosis virus. Journal of Economic Entomology, College Park, v.78, p.1373-1378, 1985b.

WIDSTRON, N.W. An evaluation of methods for measuring corn earworm injury. Journal of Economic Entomology, College Park, v.60, n.3, p.791-794, 1967.

YASEEN, M. Introduction of exotic parasites for control of Spodoptera and Heliothis in Trinidad. Proceedings of the Caribbean Food Crop Society, v.15, p.136141,1978 . 